\title{
Equifinality of basal ice facies from an Antarctic cold-based glacier
}

\author{
Suzanne SLeEwaEgen, ${ }^{1}$ Denis SAMYN, ${ }^{1}$ Sean J. FITZSimOnS, ${ }^{2}$ Reginald D. LORRAIN ${ }^{1}$ \\ ${ }^{1}$ Département des Sciences de la Terre et de l'Environnement, Faculté des Sciences, CP160/03, Université Libre de Bruxelles, B-1050 Brussels, Belgium \\ E-mail:ssleewae@ulb.ac.be \\ ${ }^{2}$ Department of Geography, University of Otago, P.O. Box 56, Dunedin, New Zealand
}

\begin{abstract}
Three debris-bearing ice facies were recognized at the base of Suess Glacier, a cold-based glacier damming a lake in Taylor Valley, South Victoria Land, Antarctica. These facies are termed "amber ice","solid facies" and "basal stratified facies". This paper uses stableisotope composition $\left(\delta \mathrm{D}\right.$ and $\left.\delta^{18} \mathrm{O}\right)$, gas content and gas composition $\left(\mathrm{CO}_{2}, \mathrm{O}_{2}\right.$ and $\left.\mathrm{N}_{2}\right)$ to develop an understanding of the processes responsible for the formation of these facies. The basal ice is characterized by a striking difference in ice properties between the innermost end of a $25 \mathrm{~m}$ long tunnel dug $200 \mathrm{~m}$ upstream from the glacier front and the front itself. At the glacier front, co-isotopic data plot along a well-defined freezing slope $(S=5.6)$, whereas, inside the tunnel, the isotopic data offset from the freezing slope and from the local meteoric water-line (which has a slope of 8.2). $\mathrm{CO}_{2}$ concentrations rise from a minimum of about $1000 \mathrm{ppmv}$ in the tunnel to about $220000 \mathrm{ppmv}$ at the front. Taken together, these characteristics strongly suggest an increasing contribution of liquid water in the formation of basal ice towards the glacier terminus. We therefore conclude that visually similar basal ice facies can have different origins.
\end{abstract}

\section{INTRODUGTION}

In geology, a facies is a rock or sediment unit that exhibits lithological, structural or faunal characteristics which enable it to be distinguished from other rock or sediment units. Although the term refers to all of the characteristics of a particular material, in practice the recognition of facies is based on the visible composition and structure of materials that are detectable in the field. As pointed out by Walker (1984), faciesbased approaches have been widely used in geology for a long time but only recently have they been applied to the study of glaciers (e.g. Lawson, 1979).

The ultimate purpose of facies designations and descriptions is to end up with an environmental interpretation. However, many facies have ambiguous interpretations and it is common to analyze all facies communally in context because the sequence in which they occur can contribute as much information as the facies themselves (Walker, 1984). At Matanuska Glacier, Alaska, U.S.A., Lawson (1979) used a combination of ice characteristics, debris concentration and the mode of debris dispersion to define englacial and basal ice facies. Since Lawson's study, facies-based approaches have become widely used and increasingly sophisticated in the study of the composition and origin of basal ice sequences (Souchez and Lorrain, 1991; Sharp and others, 1994; Hubbard and others, 1996). However, in the study of Earth systems, there is recognition that different initial states can lead to a similar end, i.e. different modes of origin may produce the same or very similar characteristics. This concept, known as equifinality, has proven to be an important one in Earth science because it works against a tendency to monocausal (single explanation) thinking.

The purpose of this paper is to examine the spatial vari- ability in basal ice facies in a cold-based Antarctic glacier in order to understand whether ice facies that have the same or similar appearance may have a different origin. We document and discuss a situation from Suess Glacier, in Taylor Valley, Antarctica, which has recently been studied by Lorrain and others (1999) and Fitzsimons and others (1999, 2000, 2001). These papers focused respectively on ice composition analyses of the marginal basal zone, and on study of the mechanical properties of the basal ice encountered in a subglacial tunnel. In the present study, we are interested in both marginal and subglacial basal zones. We describe the field site and methods used, we introduce a facies classification common for the two sites, and we present the key analytical results and their interpretation.

\section{FIELD SITE AND METHODS}

Suess Glacier is a small dry-based glacier damming a lake in Taylor Valley, South Victoria Land, Antarctica. It descends from $1750 \mathrm{~m}$ a.s.l. on the Asgard Range to about $50 \mathrm{~m}$ a.s.l. where it rests on the unconsolidated frozen sediments that compose the floor of the valley (Fig. 1). The right margin of the glacier terminus forms an 18-20 m high cliff above an iceand-debris apron adjacent to the dry-based Lake Popplewell (following Chinn, 1993). The temperature at the base of the glacier is $-17^{\circ} \mathrm{C}$.

Two series of contiguous ice blocks (about $40 \mathrm{~cm}$ high, $10 \mathrm{~cm} \times 20 \mathrm{~cm}$ wide) were sampled along the vertical: one from an excavation made in the apron and another from a shaft $4.5 \mathrm{~m}$ high dug at the end of a $25 \mathrm{~m}$ long tunnel (Fig. 1). All these ice blocks were taken with the aid of a chain-saw equipped with tungsten carbide teeth. Additionally, several ice cores were obtained with a SIPRE-type ice auger: seven 

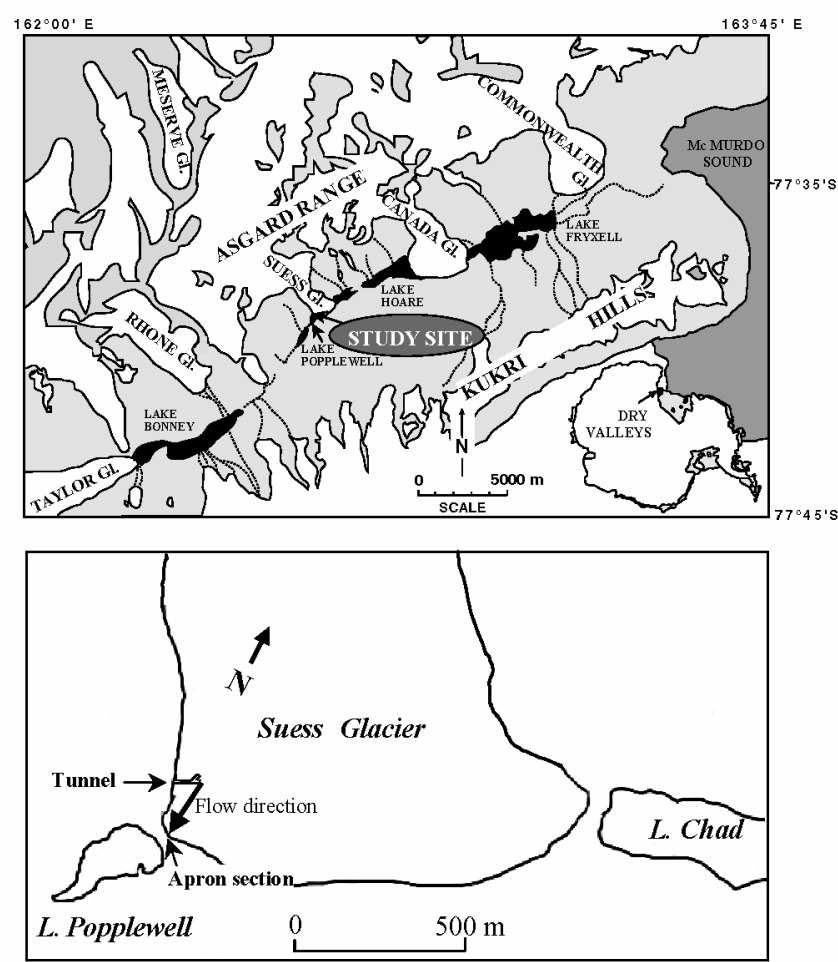

Fig. 1. Top: Location map of the study site (dotted lines represent melt streams). Bottom: Plan of the margin of Suess Glacier, showing the location of the tunnel and of the apron section, and the flow direction.

$1.6 \mathrm{~m}$ long ice cores were retrieved along a longitudinal profile from the upper surface of the glacier, and a $51 \mathrm{~m}$ long core was retrieved from above the tunnel. The ice samples were then wrapped in polyethylene bags, stored at $-18^{\circ} \mathrm{C}$ and transferred to the cold laboratory in Brussels.

In the cold room, vertical thin sections were cut along the two profiles, and samples were taken for measurements of stable isotopes $\left(\delta \mathrm{D}\right.$ and $\left.\delta^{18} \mathrm{O}\right)$, total gas content and gas composition. To avoid any contamination, a vertical $2 \mathrm{~cm}$ thick slice was cut from the surface of the samples and discarded prior to any further sampling. Because of the presence of a great amount of debris, most of the thin sections were cut using a diamond-wire saw as described by Tison (1994). For debris-free ice, the vertical thin sections were cut with a microtome. All thin sections were photographed between crossed polaroids, allowing ice-texture observations.

Sampling for isotopic analyses was done with the saw cutting horizontal short sticks, $5 \mathrm{~cm}$ long with a section of $1 \mathrm{~cm}^{2}$. After melting, the samples were analyzed at the Nuclear Research Center of Saclay in France. Results are expressed in $\delta$-units normalized to Standard Mean Ocean Water (SMOW). Precision of the measurements is $\pm 0.5 \%$ in $\delta \mathrm{D}$ and $\pm 0.1 \%$ in $\delta^{18} \mathrm{O}$. The gas analyses were performed in Brussels. The gas composition was measured on ice samples of 70-80 $\mathrm{g}$ using the technique described by Lorrain and others (1999). Total gas content was measured on samples of about $30 \mathrm{~g}$ by a melting-refreezing method described by Raynaud and others (1988) and Blunier and others (1993).

\section{ICE FACIES}

Lorrain and others (1999) and Fitzsimons and others (1999) have respectively studied the apron basal zone and the tunnel basal zone. These papers already described the basal ice units present at these two sites, and pointed to the similarity of their structures. In the present paper, we introduce a facies classification common for both sites. Several facies are present: an amber facies, a solid facies and a basal stratified facies. Because of its variability in debris and bubble content, the latter facies has been subdivided into three subfacies: laminated, dispersed bubbly and dispersed clear subfacies.

1. The amber ice facies (Fig. 2a) consists of slightly ambercolored ice containing very dispersed particles. This facies has been described by Holdsworth (1974) at Meserve Glacier which is located not far from Suess Glacier but in Wright Valley (see Fig. 1 for location).

2. The basal solid facies (Fig. 2b) consists of frozen sand and fine gravel that contains well-preserved sedimentary structures. Ice is only present in the pores between mineral grains. a

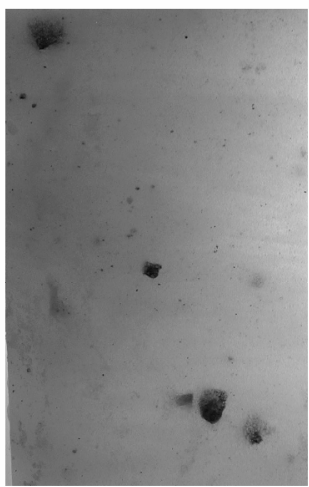

b

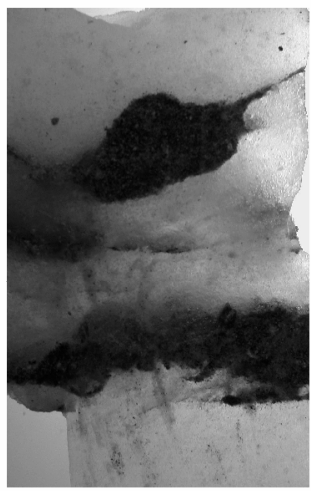

C

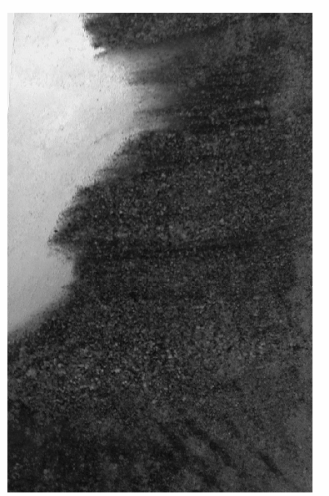

d

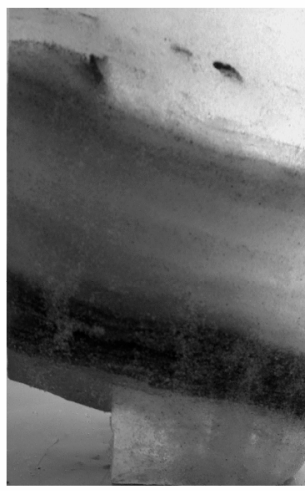

e

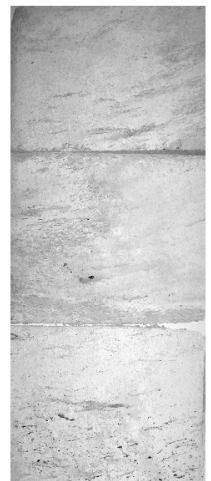

$15 \mathrm{~cm}$

Fig. 2. Pictures of the facies and subfacies encountered at the apron and tunnel sites: (a) amber ice facies; ( $b$ ) clusters of solid facies within the dispersed bubbly subfacies; ( c) laminated subfacies; ( $d$ ) dispersed bubbly subfacies with solid facies; (e) dispersed clear subfacies. 

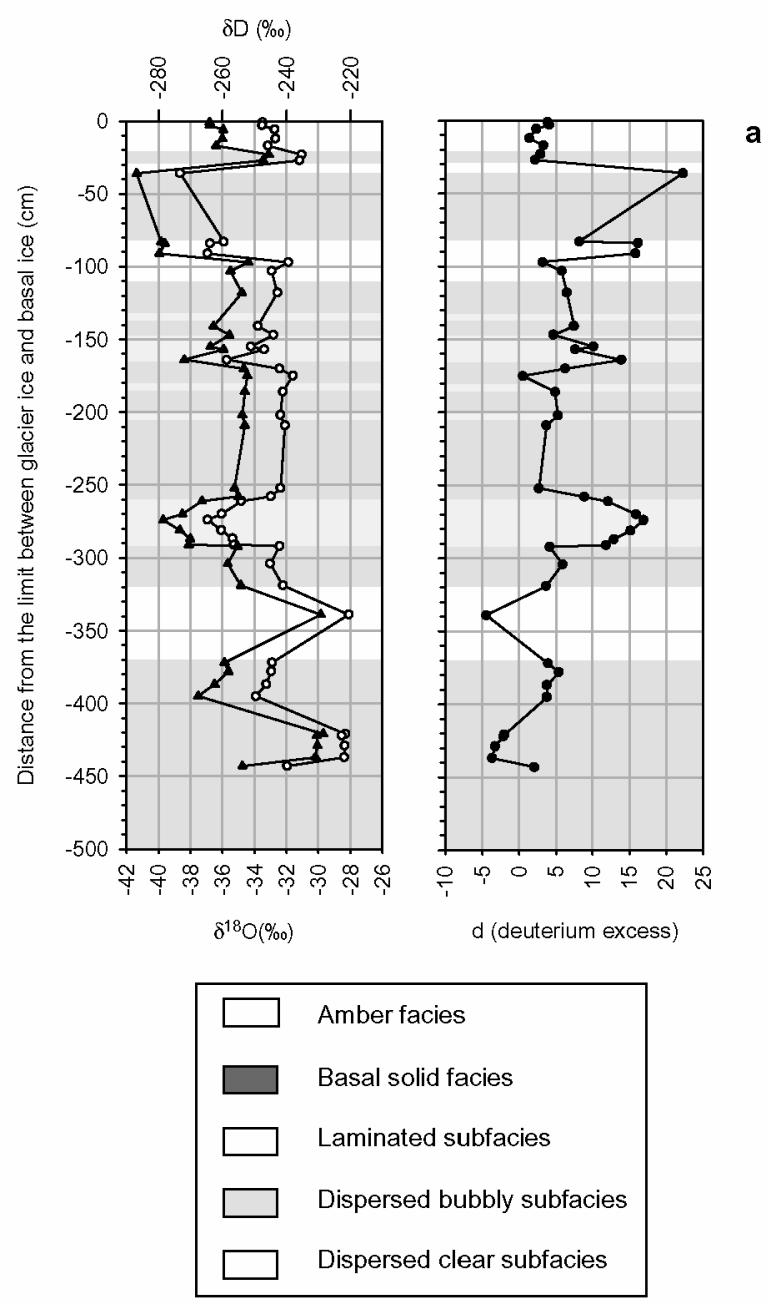

$\delta \mathrm{D}(\%)$

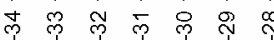

$\delta^{16} \mathrm{O}(\%)$
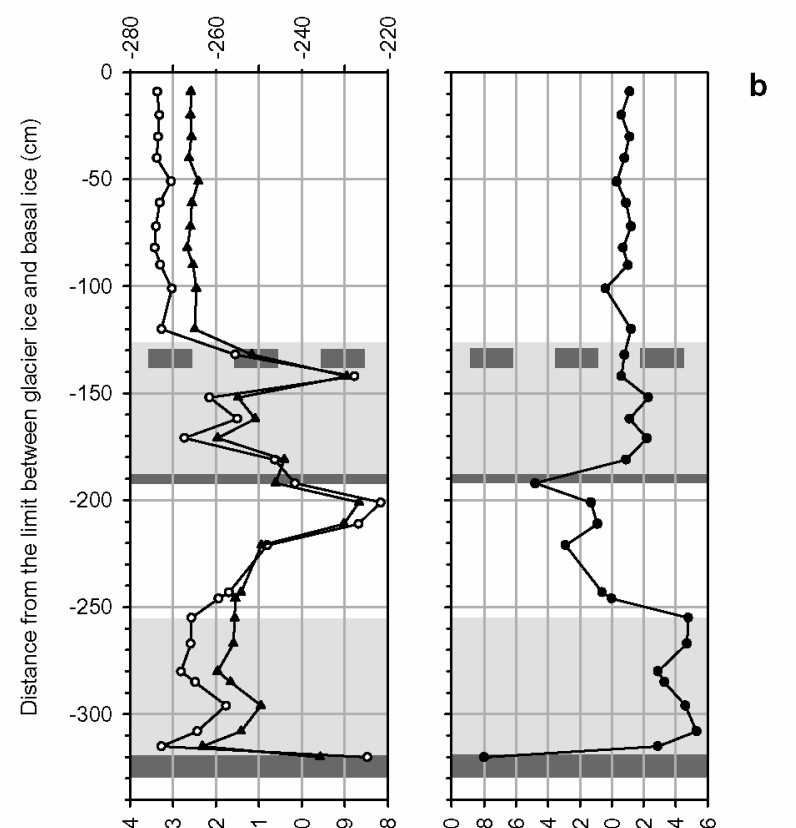

Fig. 3. Main characteristics of the basal ice: $\delta D(\mathbf{\Lambda}), \delta^{18} O$ ( 0 ) and deuterium excess profiles with the arrangement of the ice facies (a) for the apron basal ice, (b) for the tunnel basal ice.

3. The basal stratified facies, which lies below the amber ice, consists in a succession of layers that range from clean ice bands to bands with very high debris concentration, the latter being often deformed. Each of these layers belongs to one of the subfacies described below. According to the debris distribution, a laminated and a dispersed subfacies have been defined. Because of the great variability in the bubble content within the dispersed facies, the latter has been subdivided into a bubbly and a clear subfacies.

3.1. The laminated subfacies (Fig. 2c) contains stacks of clear ice layers ( $\mathrm{a}$ few $\mathrm{mm}$ to a few $\mathrm{cm}$ thick) interspersed with debris-rich laminations $<1 \mathrm{~mm}$ to a few $\mathrm{mm}$ thick. The latter sometimes are superposed, forming layers a few cm thick.

3.2. The dispersed bubbly subfacies (Fig. 2d) contains dispersed debris in variable concentrations, but the debris content is much lower than in the debris-rich laminations of the laminated subfacies. It contains numerous bubbles that are mostly elongated (from tenths of $\mathrm{mm}$ to a few $\mathrm{mm}$ long) parallel to the inferred local flow direction. It sometimes contains a few layers of clear ice. A few layers and/or clusters of basal solid facies were observed within this facies.

3.3. The dispersed clear subfacies (Fig. 2e) has the same characteristics as the dispersed bubbly subfacies, but has a very low bubble content. When visible, bubbles are concentrated in layers aligned parallel to the inferred iceflow direction.

Figure $3 \mathrm{a}$ and $\mathrm{b}$ show how the different facies are arranged in the apron and in the tunnel profiles. The thickness and the relative position of the facies differ between the two locations. The basal amber facies, for example, is only $20 \mathrm{~cm}$ thick at the apron, which is very thin in comparison with the $125 \mathrm{~cm}$ thickness in the tunnel. No solid facies was sampled in the apron sequence, but two layers with a very high debris concentration were observed within the dispersed clear and bubbly subfacies. These debris layers, whose debris content is close to that of the solid facies, are respectively located between -320 and $-370 \mathrm{~cm}$ and between -429 and $-437 \mathrm{~cm}$. In the tunnel profile, the solid facies appears only as layers and clusters within the stratified facies. However, elsewhere in the tunnel it can be observed as a thick layer (up to $0.6 \mathrm{~m}$ thick and averaging $0.5 \mathrm{~m}$ thick in the rear part of the tunnel) between the amber and the stratified facies, as presented in figure 3 in Fitzsimons and others (1999), which shows a synthetic view of several local observations from Suess tunnel.

\section{RESULTS}

\section{Apron}

In the amber ice, crystals are equigranular and very small (mean diameter $0.7 \mathrm{~mm}$ ). In the stratified facies, crystal size varies between $\sim 1$ and $\sim 10 \mathrm{~mm}$ in diameter, the biggest ice crystals being observed in the dispersed clear subfacies, and the smallest ones in the laminated subfacies.

The isotopic profiles of the apron site are presented in Figure $3 \mathrm{a}$. The $\delta^{18} \mathrm{O}$ and $\delta \mathrm{D}$ values in the amber ice have a narrow range $(-33.51$ to $-32.67 \%$ and -264 to $-260 \%$, respectively) while they vary widely in the stratified facies $(-38.64$ to $-28.1 \%$ of $\delta^{18} \mathrm{O}$ and -286.8 to $-228.5 \%$ for $\left.\delta \mathrm{D}\right)$. The laminated subfacies presents generally low $\delta$ values $(-36.93$ to $-32.38 \%$ in $\delta^{18} \mathrm{O}$ and -278.5 to $-253.8 \%$ in $\left.\delta \mathrm{D}\right)$. Besides, the dispersed bubbly subfacies shows a large range of $\delta$ values $(-33.92$ to $28.31 \%$ in $\delta^{18} \mathrm{O}$ and -267.6 to $-228.5 \%$ in $\left.\delta \mathrm{D}\right)$. This subfacies 
Table 1. Results of gas analyses of a meteoric ice sample, and of basal ice samples from the tunnel and from the apron sites

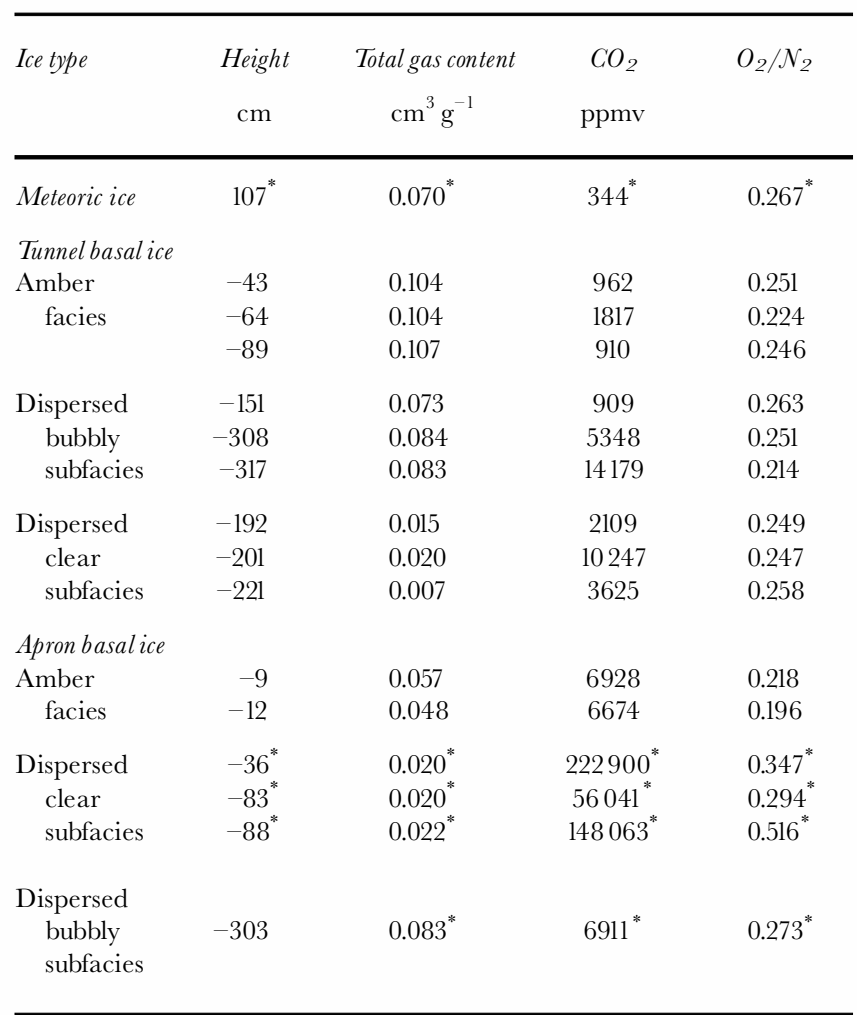

Notes: Values with a * are from Lorrain and others (1999). Heights are from the limit between glacier ice and basal ice.

presents a very narrow range of isotopic values in the middle part of the profile, but it shows high $\delta$ values in the lower part. The clear ice subfacies contains the lowest and the highest $\delta$ values of the whole profile $\left(-38.64\right.$ to $-28.1 \%$ for $\delta^{18} \mathrm{O}$ and 286.8 to $-228.5 \%$ for $\delta \mathrm{D})$. The deuterium excess $(d=\delta \mathrm{D}-$ $8 \delta^{18} \mathrm{O}$ ) varies from -4.5 to 22.3 , as a mirror image of the $\delta$ profiles.

Results of the gas analyses from different ice facies (Table 1) show that $\mathrm{CO}_{2}$ concentrations range from 6674 to 229000 ppmv and that $\mathrm{O}_{2} / \mathrm{N}_{2}$ ratios vary between 0.20 and 0.52 . The total gas content is generally lower than in meteoric ice.

\section{Tunnel}

Except in the amber ice, ice crystals are smaller in the tunnel than at the apron. In the stratified facies, the biggest ice crystals $(\sim 5 \mathrm{~mm})$ are observed in the dispersed clear subfacies, whereas the smallest ice crystals $(\sim 0.7 \mathrm{~mm})$ are encountered in the debris-rich layers. The dispersed bubbly ice is made up of crystals $1.5-2.5 \mathrm{~mm}$ in mean diameter.

The isotopic profiles of the tunnel site are presented in Figure $3 \mathrm{~b} . \delta \mathrm{D}$ and $\delta^{18} \mathrm{O}$ values for the amber ice are similar at the glacier margin and in the tunnel (values for the tunnel amber ice are -33.43 to $-33.03 \%$ for $\delta^{18} \mathrm{O}$ and -266.7 to $-264.1 \%$ for $\delta \mathrm{D}$ ). There are, however, strong contrasts between the $\delta$ values for the stratified facies in the two locations. In the tunnel, the highest isotopic values (up to $-28.17 \%$ for $\delta^{18} \mathrm{O}$ and $-226.7 \%$ o for $\left.\delta \mathrm{D}\right)$ were found in the dispersed clear subfacies, and in a sample at $-142 \mathrm{~cm}$ that corresponds to a clear layer in the dispersed bubbly subfacies. This situation of higher isotopic values in the clear ice is similar to what Iizuka and others (2001) have observed for samples from Hamna Glacier, Sôya Coast, East Antarctica.

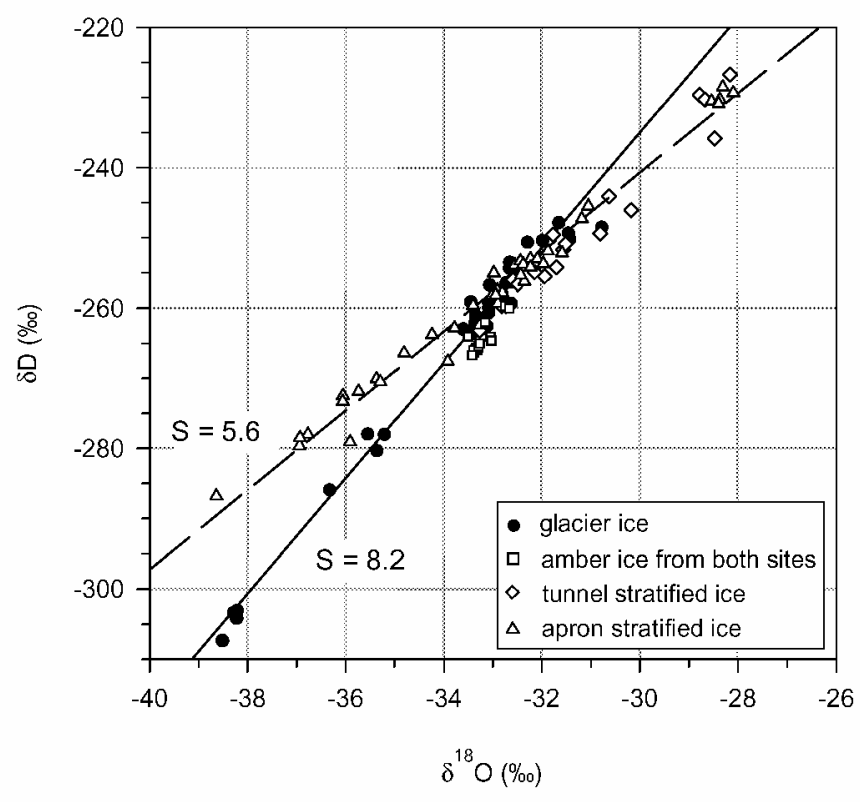

Fig. 4. $\delta D-\delta^{18} \mathrm{O}$ diagram showing samples from: the surface ice cores and the $51 \mathrm{~m}$ long ice core (-); the amber ice from apron and tunnel sites $(\square)$; the tunnel stratified ice $(\diamond)$; and the apron stratified ice $(\triangle)$. The solid line corresponds to the $L M W L$ (regression line from the glacier ice samples); the dashed line corresponds to the regression line from the apron basal stratified facies. $S$ is the value of the slope of the nearby regression line.

The deuterium excess $(d)$ varies in a narrow range $(-0.4$ to 2.3$)$ from the top of the sequence all the way to $-180 \mathrm{~cm}$. $d$ is higher $(2.9-5.3)$ in the dispersed bubbly subfacies between -253 and $-318 \mathrm{~cm}$. $d$ is lower $(-4.8$ to -0.6$)$ in the dispersed clear and in the laminated subfacies, and reaches a much lower value in the solid facies near the base of the profile $(-8)$.

Results of the gas analyses from different ice facies are presented in Table $1 . \mathrm{CO}_{2}$ concentrations range from near 909 ppmv in the amber ice to a concentration of 14179 ppmv in the dispersed bubbly subfacies at $-317 \mathrm{~cm}$. $\mathrm{CO}_{2}$ concentrations are constant in the amber ice and have a large range in the two other subfacies. $\mathrm{O}_{2} / \mathrm{N}_{2}$ ratios vary between 0.21 and 0.26 . Total gas content is very high in the amber facies (about $0.1 \mathrm{~cm}^{3} \mathrm{~g}^{-1}$ ) and in the dispersed bubbly facies (about $0.8 \mathrm{~cm}^{3} \mathrm{~g}^{-1}$ ). These values are in the range reported by Martinerie and others (1992) for glacier ice from polar ice cores. In contrast, the values from the dispersed clear facies are much lower: as low as $0.007 \mathrm{~cm}^{3} \mathrm{~g}^{-1}$. These gas data differ from those of the apron basal ice, which has generally a higher $\mathrm{CO}_{2}$ concentration and a lower total gas content (Table 1).

\section{DISGUSSION}

\section{Isotopic and gas composition}

The results presented above demonstrate that although the basal ice facies exposed at the apron and inside the tunnel look the same, they clearly present differences in ice composition.

Figure 4 shows the $\delta \mathrm{D}-\delta^{18} \mathrm{O}$ diagram for the different ice samples taken in the Suess Glacier environment. The local meteoric water-line (LMWL) has been obtained from glacier ice samples collected along the longitudinal profile 
and glacier ice samples from the $51 \mathrm{~m}$ core cited above. The slope obtained has the following equation: $\delta \mathrm{D}=8.21 \delta^{18} \mathrm{O}+$ $11.5\left(r^{2}=0.98\right)$, which is nearly equivalent to the LMWL defined in Lorrain and others (1999) from the samples of the glacier surface only. The amber ice samples do not plot significantly away from this line, indicating that amber ice cannot be isotopically distinguished from glacier ice, at least at the scale of our sampling, which can be coarser than the scale of potential individual freezing events.

In contrast, ice samples from the stratified facies at the apron site are aligned on a much lower slope, the value of which is 5.6 (Fig. 4). It can be considered as a freezing slope since its value is nearly identical to that calculated by Lorrain and others (1999) for this environment. The fact that this slope is lower than 8.21 (slope of the LMWL) explains the mirror image of the $d$ profile vs the $\delta$ profiles (Fig. $3 \mathrm{a}$ and b). Another striking feature of the isotopic composition of the apron ice samples is that some samples, from different ice facies, are considerably depleted in heavy isotopes of oxygen and hydrogen along the freezing slope. Such characteristics imply the more-or-less complete freezing of liquid-water volumes. This has been theoretically and experimentally developed by Jouzel and Souchez (1982) and Souchez and Jouzel (1984). As the freezing front progresses into water, ice is enriched in heavy isotopes with regard to water. When the residual liquid water becomes very restricted, it impoverishes in deuterium and oxygen-18, and the forming ice is therefore impoverished in heavy isotopes as well. Such isotopic results are consistent with the hypothesis that basal ice at Suess apron has been built up by ice and debris accretion to the sole of the glacier during its advance into a wet-based lake (Fitzsimons, 1996; Lorrain and others, 1999, 2002).

In the tunnel, the basal ice samples from the stratified facies are generally enriched in heavy isotopes compared to the glacier ice samples and are clearly offset from the LMWL. They are also not aligned on the freezing slope obtained from the apron ice samples. Such a situation nevertheless implies phase changes, probably from minor liquid-water volumes. This indicates that liquid water makes a less significant contribution to the formation of basal ice in the tunnel (minor contribution) than at the apron (major contribution).

The gas data also point to this variable contribution at the apron and in the tunnel. The basal ice samples from the apron show some very high $\mathrm{CO}_{2}$ concentrations, high $\mathrm{O}_{2} / \mathrm{N}_{2}$ ratios and low total gas contents, in striking contrast to meteoric ice (Table 1). Lorrain and others (1999) explained these characteristics by considering freezing of liquid water. Indeed, this process causes gas rejection and preferential incorporation of $\mathrm{CO}_{2}$ because of its higher solubility. Furthermore, as mentioned by Lorrain and others (1999), some organic processes associated with the presence of liquid water may have produced the unusual measured gas composition.

In comparison with what is shown at the apron, the basal ice samples from the tunnel generally present lower $\mathrm{CO}_{2}$ concentrations and lower $\mathrm{O}_{2} / \mathrm{N}_{2}$ ratios, but higher total gas content (Table 1). In comparison with the glacier ice above, the basal ice from the tunnel presents much higher $\mathrm{CO}_{2}$ concentrations and slightly lower $\mathrm{O}_{2} / \mathrm{N}_{2}$ ratios. Concerning its total gas content, however, the basal ice shows the same values as for the above glacier ice $\left(0.070 \mathrm{~cm}^{3} \mathrm{~g}^{-1}\right)$, except for the clear ice samples. These results indicate that the tunnel basal ice has undergone an increase in $\mathrm{CO}_{2}$ without significant loss of gas.

The two different signatures for tunnel basal ice and

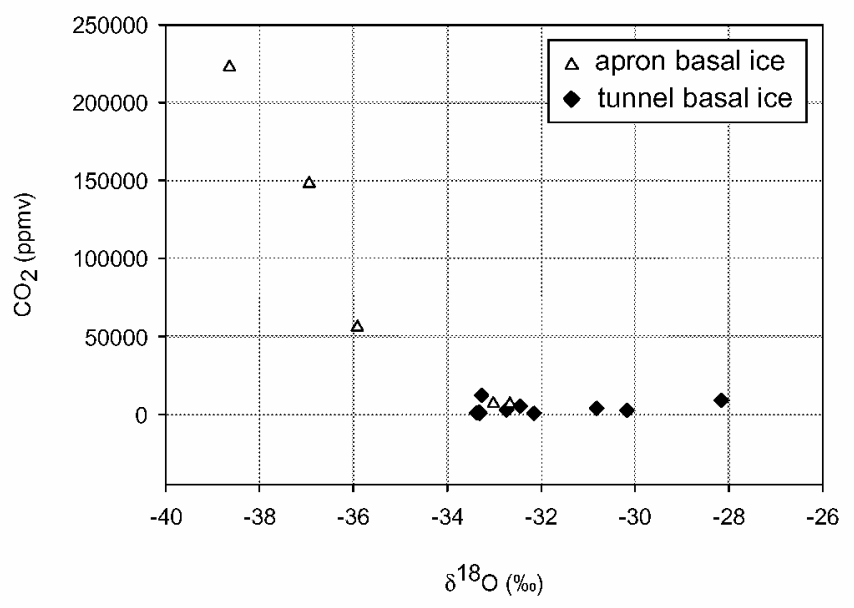

Fig. 5. $\mathrm{CO}_{2}-\delta^{18} \mathrm{O}$ diagram showing samples from apron basal ice $(\triangle)$ and tunnel basal ice (

apron basal ice can also be illustrated by a $\mathrm{CO}_{2}-\delta^{18} \mathrm{O}$ diagram (Fig. 5). In this figure, the very high $\mathrm{CO}_{2}$ concentrations from the apron correspond to depleted $\delta^{18} \mathrm{O}$ values, while $\mathrm{CO}_{2}$ concentrations in the tunnel are independent of $\delta^{18} \mathrm{O}$ values. These data reinforce the interpretation given about the occurrence of complete freezing of liquid-water volumes at the apron.

Thus, while the microbiological activity is not excluded as a mechanism to change gas composition in basal ice, lower $\mathrm{CO}_{2}$ concentrations in the tunnel compared to the apron, combined with lower $\mathrm{O}_{2} / \mathrm{N}_{2}$ ratios and higher total gas contents, suggest that freezing of liquid water has played a lesser role in the formation of basal ice in the tunnel than in the apron.

\section{Build-up and spatial continuity}

At the base of Meserve Glacier cited above, amber ice is in direct contact with the bed except in a $20 \mathrm{~m}$ wide zone toward the marginal ice cliff. In this zone the amber layer rises gradually and over-rides an apron made of marginal debris containing ice blocks fallen from the cliff, windblown snow and refrozen meltwater (Holdsworth, 1974; Cuffey and others, 2000). In contrast, at the base of Suess Glacier, even at $25 \mathrm{~m}$ inside the tunnel, the amber ice lies on top of $2.15 \mathrm{~m}$ of stratified ice, well above the effective bed (defined as the place where displacement is zero). Although the formation of the stratified layer has been attributed to zones of weakness such as cavities or ice lenses within the glacier substrate (Fitzsimons and others, 2001), the entrainment processes have yet to be fully understood. However, it seems clear that the stratified facies has been formed by entrainment of fragments of the substrate at the base of the glacier. Such a mechanism implies that the amber ice that lies above the stratified facies has been formed upstream of and before the stratified facies.

The flow direction (see Fig. 1) and the similarity of facies exposed in the tunnel and at the apron indicate that a spatial continuity exists between these two locations. However, the strong differences in ice composition between the two sequences suggest that important changes occur towards the margin. Strong arguments have been developed in favour of water freezing and debris accretion to explain the apron ice, but it is clear that, despite the similarities of 
facies, the basal ice in the tunnel has not been formed by the same mechanism.

\section{GONCLUSION}

Isotopic analyses and gas data indicate that there is a strong spatial variability in the composition of basal ice in Suess Glacier. The strong contrast in isotopic composition suggests that liquid water plays an increasingly important role in basal ice formation toward the glacier margin.

A comparison of the ice composition data presented in this paper, together with descriptions of facies from the tunnel and ice-marginal sampling site, demonstrate that ices with similar visible characteristics can have distinctly different chemical composition. This observation suggests that facies descriptions can be unreliable indicators of origin and that careful compositional analysis is required to decipher the mechanisms involved.

\section{AGKNOWLEDGEMENTS}

We would like to thank Antarctica New Zealand for providing the logistical support for this study. The Marsden Fund of the Royal Society of New Zealand and the University of Otago provided financial support. Thanks are also due to M. Stiévenard from the Nuclear Research Center in Saclay, France, for the isotopic analyses and to R. Souchez for his constructive comments on an early draft of this paper. This paper is a contribution to the Belgian Scientific Program on Antarctica (OSTC-SPSD II). D. Samyn acknowledges grant support from Fonds pour la formation à la Recherche dans l'Industrie et dans l'Agriculture (FRIA), Belgium. We are also indebted to B. Hubbard for critical reviews of the paper, which resulted in substantial improvements to the text.

\section{REFERENGES}

Blunier, T. and6 others. 1993. Atmospheric methane record from a Greenland ice core over the last 1000 years. Geophys. Res. Lett., 20 (20), 2219-2222.

Chinn, T. J. 1993. Physical hydrology of the Dry Valley lakes. In Green, W. J. and E. I. Friedmann, eds. Physical and biogeochemical processes in Antarctic lakes. Washington, DC, American Geophysical Union, 1-51. (Antarctic Research Series 59.)

Cuffey, K. M. and 8 others. 2000. Entrainment at cold glacier beds. Geology, $28(4), 351-354$

Fitzsimons, S. J. 1996. Formation of thrust-block moraines at the margins of dry-based glaciers, south Victoria Land, Antarctica. Ann. Glaciol., 22, 68-74.

Fitzsimons, S.J., K.J. McManus and R. D. Lorrain. 1999. Structure and strength of basal ice and substrate of a dry-based glacier: evidence for substrate deformation at sub-freezing temperatures. Ann. Glaciol., 28, 236-240.

Fitzsimons, S. J., R. D. Lorrain and M. J. Vandergoes. 2000. Behaviour of subglacial sediment and basal ice in a cold glacier. In Maltman, A. J., B. Hubbard and M. J. Hambrey, eds. Deformation of glacial materials. London, Geological Society, 181-190. (Special Publication 176. )

Fitzsimons, S. J., K. J. McManus, P. Sirota and R. D. Lorrain. 2001. Direct shear tests of materials from a cold glacier: implications for landform development. Quat. Int., 86(1), 129-137.

Holdsworth, G. 1974. Meserve Glacier, Wright Valley, Antarctica: Part 1. Basal processes. Ohio State Univ. Inst. Polar Stud. Rep. 37.

Hubbard, B., M. Sharp and W.J. Lawson. 1996. On the sedimentological character of Alpine basal ice facies. Ann. Glaciol., 22, 187-193.

Iizuka, Y., H. Satake, T. Shiraiwa and R. Naruse. 2001. Formation processes of basal ice at Hamna Glacier, Sôya Coast, East Antarctica, inferred by detailed co-isotopic analyses. F. Glaciol., 47(157), 223-231.

Jouzel, J. and R. A. Souchez. 1982. Melting-refreezing at the glacier sole and the isotopic composition of the ice. F. Glaciol., 28(98), 35-42.

Lawson, D. E. 1979. Sedimentological analysis of the western terminus region of the Matanuska Glacier, Alaska. CRREL Rep.79-9.

Lorrain, R. D., S. J. Fitzsimons, M. J. Vandergoes and M. Stiévenard. 1999 Ice composition evidence for the formation of basal ice from lake water beneath a cold-based Antarctic glacier. Ann. Glaciol., 28, 277-281.

Lorrain, R., S. Sleewaegen, S. Fitzsimons and M. Stiévenard. 2002. Ice formation in an Antarctic glacier-dammed lake and implications for glacier-lake interactions. Arct. Antarct. Alp. Res., 34(2), 150-158.

Martinerie, P., D. Raynaud, D. M. Etheridge, J.-M. Barnola and D. Mazaudier. 1992. Physical and climatic parameters which influence the air content of polar ice. Earth Planet. Sci. Lett., 112(1-4), 1-13.

Raynaud, D., J. Chappellaz, J.-M. Barnola, Ye. S. Korotkevich and C. Lorius. 1988. Climatic and $\mathrm{CH}_{4}$ cycle implications of glacial-interglacial $\mathrm{CH}_{4}$ change in the Vostok ice core. Nature, 333(6174), 655-657.

Sharp, M., J. Jouzel, B. Hubbard and W. Lawson. 1994. The character, structure and origin of the basal ice layer of a surge-type glacier. F. Glaciol., 40(135), 327-340.

Souchez, R. A. and J. Jouzel. 1984. On the isotopic composition in $\delta \mathrm{D}$ and $\delta^{18} \mathrm{O}$ of water and ice during freezing. 7. Glaciol., 30 (106), 369-372.

Souchez, R.A. and R. D. Lorrain. 1991. Ice composition and glacier dynamcis. Berlin, etc., Springer-Verlag. (Springer Series in Physical Environment 8.)

Tison, J.-L. 1994. Diamond wire-saw cutting technique for investigating textures and fabrics of debris-laden ice and brittle ice. 7. Glaciol., 40(135), 410-414.

Walker, R. G. 1984. Facies models. Secondedition. Toronto, Geological Association of Canada. (Geoscience Canada Reprint Series 1.) 